\title{
Effect of genotype on cytoplasmic incompatibility between two species of Nasonia
}

\author{
JOHANNES A. J. BREEUWER \& JOHN H. WERREN \\ Department of Biology, University of Rochester, Rochester, NY 14627, U.S.A.
}

\begin{abstract}
Cytoplasmically inherited bacteria cause bidirectional incompatibility between two species of the parasitoid wasp genus Nasonia. These bacteria belong to the alpha sub-division of the Proteobacteria. Normally, hybrid (female) offspring are not produced in interspecific crosses. Elimination of the cytoplasmically-inherited bacteria by antibiotic treatments restores compatibility, i.e. hybrid females are produced. Bidirectional incompatibility could be caused directly, by differences between the bacteria of the two species, or indirectly, by the different interactions of the bacteria with host species genomes. To distinguish between these two possibilities, genetic crosses were set up to introduce the nuclear genome of each wasp species into the cytoplasmic (microbial) background of the other. These strains were then tested for compatibility to the infected parental species. Individuals from both reciprocal introgressions were only compatible with individuals that had the same cytoplasm, independent of nuclear background. This indicates that compatibility type is independent of the host genotype and is based on differences between cytoplasmic bacteria of the two Nasonia species. However, compatibility differences from interactions between the bacteria and the other cytoplasmically inherited elements (e.g. mitochondria) have not been ruled out.
\end{abstract}

Keywords: bacteria, cytoplasmic incompatibility, genetics, Hymenoptera, Nasonia, symbiont.

\section{Introduction}

Cytoplasmically inherited reproductive incompatibility between strains (or species) has been observed in many insects (Laven, 1957; Saul, 1961; Kellen et al., 1981; Trpis et al., 1981; Hsiao \& Hsiao, 1985b; Wade \& Stevens, 1985; Hoffmann et al., 1986; Hoffmann, 1988; Breeuwer \& Werren, 1990; O’Neill \& Karr, 1990). In most cases maternally inherited micro-organisms have been implicated as the causative agent. Evidence comes from cytological observations of micro-organisms in reproductive tissues (Yen \& Barr, 1973; Wright \& Barr, 1980; Kellen et al., 1981; Trpis et al., 1981; Hsiao \& Hsiao, 1985a; Binnington \& Hoffmann, 1989; O’Neill, 1989; Breeuwer \& Werren, 1990; O'Neill \& Karr, 1990), alteration of compatibility through antibiotic treatment of infected individuals (Yen \& Barr, 1971; Kellen et al., 1981; Trpis et al., 1981; Wade \& Stevens, 1985; Richardson et al., 1986; Hoffmann, 1988; Hoffmann \& Turelli, 1988; Breeuwer \& Werren, 1990; O’Neill \& Karr, 1990; Montchamp-Moreau et al., 1991), and identification of bacteria via sequencing $16 \mathrm{~S}$ ribosomal genes from infected strains. These bacteria fall in the alpha subdivision of Proteobacteria, and show high sequence similarity ( $>95$ per cent) despite being found in diverse insect taxa (Breeuwer et al., 1992; O'Neill et al., 1992; Rousset et al., 1992). Based on high 16S sequence similarity, cytoplasmic incompatibility bacteria are likely to belong to the same genus Wolbachia.

Typically, cytoplasmic incompatibility is unidirectional; males of one strain are incompatible with females from another strain, whereas the reciprocal cross is compatible and produces normal progeny. However, bidirectional incompatibility, in which both reciprocal crosses are incompatible, has been found between strains of the mosquito Culex pipiens (Laven, 1957, 1967), the fruitfly Drosophila simulans (O'Neill \& Karr, 1990; Nigro, 1991; Montchamp-Moreau et al., 1991) and between species of the parasitoid wasp genus Nasonia (Breeuwer \& Werren, 1990).

In Nasonia, it was previously demonstrated that hybridization between $N$. vitripennis and $N$. giraulti is 
prevented by bacteria (Breeuwer \& Werren, 1990). Cytogenetic examination shows that, following mating in interspecific crosses, sperm do fertilize eggs. However, in the first mitotic division the paternal chromosomes condense improperly and are eventually lost (Breeuwer \& Werren, 1990). A similar pattern occurs in unidirectional incompatibility between laboratory strains of $N$. vitripennis (Ryan \& Saul, 1968). Paternal genome loss reconstitutes haploidy in the embryo, which therefore develops into a male that inherits only the maternal genome (owing to haplodiploid sex determination). Elimination of micro-organisms restores compatibility, and hybrid female offspring are produced. Thus even though both species carry a heritable bacterium, which typically does not affect compatibility within species, they are involved in incompatibility between species.

Bidirectional incompatibility between species could be caused by either species-specific differences in the bacteria, or by different bacterial interactions with the respective host genomes (i.e. $N$. giraulti vs. $N$. vitripennis). More specifically, the cytoplasmic incompatibility microbe found in $N$. giraulti may be inherently bidirectionally incompatible with the microbe of $N$. vitripennis, or bidirectional incompatibility may result from different interactions of the micro-organism(s) with the host genomes. For example, in each species nuclear genes could have evolved to suppress incompatibility, whereas it is still expressed in interspecific crosses. To distinguish between the two possibilities (microbe or host genome differences), it is necessary to introduce the cytoplasmic incompatibility microbe of one species into the nuclear background of the other species, and then test whether its incompatibility relationships have changed.

The two hypotheses were tested by comparing incompatibility relationships of parental species with those of backcrossed individuals, in which the genotype of one species was introgressed into the infected cytoplasm of the other species over successive generations.

\section{Materials and methods}

The general biology of Nasonia is described by Whiting (1967). In the laboratory Nasonia were raised on fleshfly pupae, Sarcophaga bullata, at $25^{\circ} \mathrm{C}$ and constant light. Under these conditions generation time is 14 days. Two wild-type (infected) strains were used: $N$. vitripennis (LablI laboratory strain, Leiden, The Netherlands) and $N$. giraulti (RV2, collected in Rochester, NY, U.S.A., 1986). These strains harbour cytoplasmic incompatibility micro-organisms (CIM), as do all field-collected strains so far examined. Cured lines were derived from the wild-type strain of each species by feeding females an antibiotic $\left(1 \mathrm{mg} \mathrm{ml}^{-1}\right.$ tetracycline in 10 per cent sucrose) prior to egg laying. This was repeated for three generations, at which time no micro-organisms could be detected in the cytoplasm of freshly laid eggs stained with 2 per cent lacmoid (Breeuwer \& Werren, 1990). These cured strains, labelled Asymc and RV2T, respectively, have been maintained free of cytoplasmic incompatibility microorganisms for over 5 years of laboratory maintenance.

\section{Terminology}

Individuals from infected (wild-type) strains are referred to as 'symbiont' and have a 's' cytotype, because they harbour the symbiont bacteria. Cured or uninfected strains are indicated as 'asymbiont' and have an 'a' cytotype, because they are free of symbiont bacteria. An individual is designated by genotype, with cytotype indicated between brackets. Analogous to an individual's genotype, the term cytotype refers to the heritable cytoplasmic factors that reside in the cytoplasm of an individual. A cytotype is typically inherited only via the mother. For both genotype and cytotype, $V$ stands for $N$. vitripennis and $G$ for $N$. giraulti. Thus, Asymc is designated as $V[V a]$, whereas LabII is $V[V s]$. Note that both strains have the same nuclear background, as is also the case for $G[G a]$ and $G[G s]$. The genotype of individuals from introgression lines is described by the paternal genotype, the number of introgression generations followed by the original maternal genotype (e.g. $G 5 V[V s]$ is derived from an original cross between $\mathrm{F}_{1}$ hybrid $\left(G[G a] \sigma^{*} \times V[V s]\right.$ 우 $)$ \& backcrossed to $G[G a] \sigma^{\prime}$ for an additional four generations).

\section{Introgression lines}

The nuclear genome of each species was introgressed into the symbiont cytotype of the other species by repeated backcrossing (Fig. 1). Lines were started with reciprocal crosses between asymbiont males and symbiont females of the parental species $\left(V[V a] \sigma^{\prime} \times G\right.$ $[G s] \propto$ and $G[G a] \sigma^{\prime} \times V[V s]$ \&). Resulting hybrid females were backcrossed to asymbiont males of the paternal species for up to 16 generations. After 16 backcross generations, a line, $G 16+V[V s]$, was established from offspring of $G[G a] \delta^{\prime} \times G 16 V[V s]$ o , and has been maintained by within strain mating without further backcrossing for over a year. The reciprocal introgression of $V$ genotype into a [Gs] cytotype was terminated after five backcross generations. 


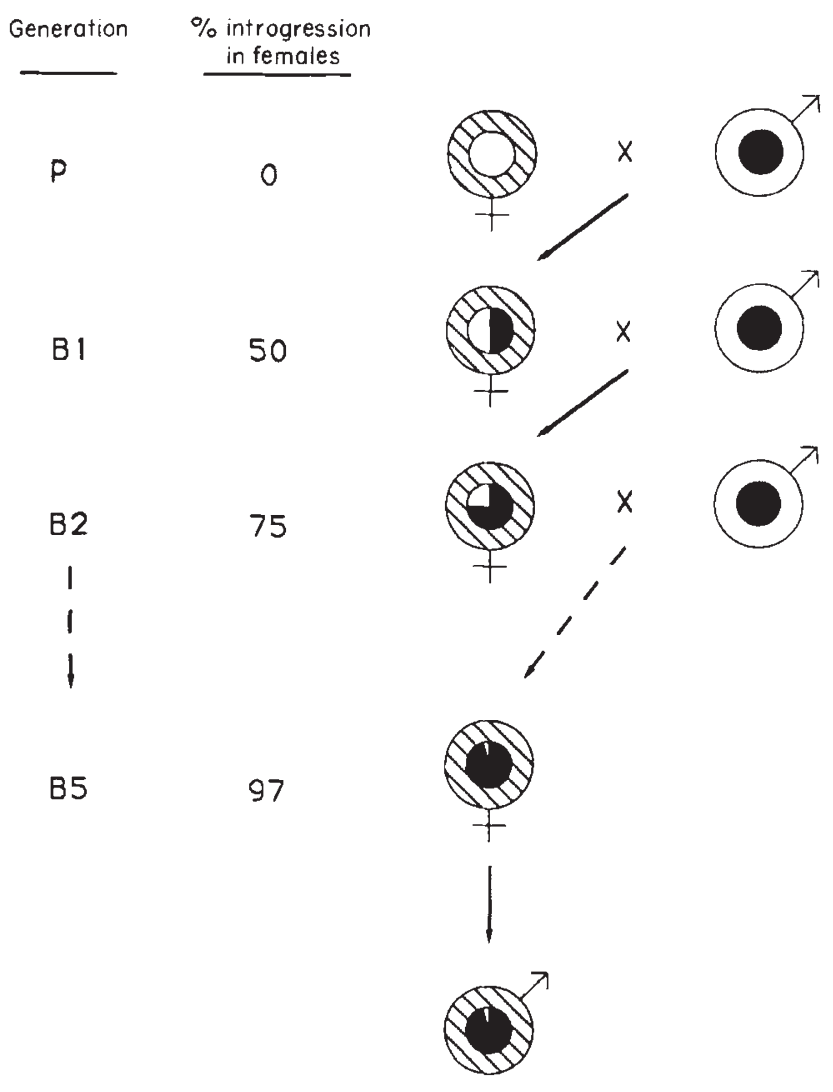

Fig. 1 Diagram of the introgression scheme showing the nuclear substitution (inner circle) of the maternal genotype (blank) by the paternal genotype (black). Cytotype (outer circle) is only maternally inherited. Percentage nuclear substitution in females is calculated as $1-\left(1-\frac{1}{2} n\right)$, where $n$ is the number of backcross generations.

\section{Assumptions of the introgression process}

In theory, each backcross generation will replace half of the residual maternal nuclear genome with the paternal nuclear genome in the female (diploid) progeny (Fig. 1). Thus, 97 per cent of the original maternal genome will be substituted by the paternal genome after five backcross generations, assuming normal levels of recombination. On the other hand, the heritable cytoplasmic factors are only maternally inherited; the male sperm does not contribute cytoplasm to the egg. Therefore, backcrossed lines will carry the substituted paternal genome in a cytoplasmic background that contains the original maternal heritable cytoplasmic factors.

Backcrossed lines are expected to contain the substituted paternal genome combined with maternally inherited CIM. Typically, three assumptions are made about the backcross process (Grun, 1976): (i) the heritable cytoplasmic factors do not change during back- crossing; (ii) sperm does not contribute cytoplasm to the egg; and (iii) there is no preferential retention of maternal genes among recombinant eggs.

The first assumption was the main focus of this study. The second assumption is usually taken for granted. Currently, there is no evidence for even low levels of paternal transmission of CIM in Nasonia. Very low levels may occur in the CIM of $D$. simulans (Hoffmann \& Turelli, 1988). By using asymbiont males for backcrosses, potential paternal transmission of CIM was eliminated. The third assumption requires genetic markers to distinguish between the genotypes of the two species. No suitable visible markers are available in Nasonia. However, the two Nasonia species differ in antennal shape, male wing morphology $(N$. vitripennis males have brachypterous wings whereas $N$. giraulti males have much larger and broader wings) and $N$. giraulti females lack marginal fringes or bristles on the forewing (Darling \& Werren, 1989). These characters can be used as an index for the introgression of linked nuclear genes.

\section{Testing compatibility}

Backcrossed lines were assessed for compatibility by crosses to symbiont parental strains. Test crosses were done at the fifth, tenth and sixteenth $(+)$ generation of introgression of $G$ genotype in $[V S]$ cytotype and at the fifth generation for the reciprocal introgression, $V$ genotype in $[G s]$ cytotype. For all experimental crosses, females and males were collected as virgin pupae. On emergence, pair matings were performed. Mating was observed to exclude crosses that produced only male progeny as a result of females that remained unmated. Pairs that did not copulate within $30 \mathrm{~min}$ were discarded from the analysis. After $24 \mathrm{~h}$, males were removed and females were provided with two hosts for oviposition. Incompatibility type was subsequently determined by scoring offspring sex ratio. Presence of female offspring indicates that the cross is compatible.

\section{Female compatibility}

This was tested in crosses to infected males of the parental species. In addition to mating observations, females from each strain were crossed to cured males of the parental species to determine if mating resulted in insemination. Asymbiont males are compatible with any female, regardless of her cytotype and genotype (Breeuwer \& Werren, 1990). Therefore, observation of all male progeny in these crosses will provide information on the occurrence of uninseminated females despite observed copulations. 


\section{Male compatibility}

The male compatibility of the introgression lines was tested in crosses to females from infected parental strains. Because males develop from unfertilized eggs, genomic substitution in males is one generation behind that of backcrossed females (Fig. 1). In other words, male offspring have the same level of introgression as their mother, rather than their sisters.

\section{Results}

$\mathrm{N}$. giraulti genotype into $\mathrm{N}$. vitripennis symbiont cytotype

Compatibility type of females of the symbiont maternal species, $V[V s]$, is shown in Table 1 . They are compatible with their own $V[V s]$ males, but incompatible with $G[G s]$ males. In contrast, female offspring were produced in crosses with asymbiont males of both species. This confirms the earlier compatibility relationships found between $N$. vitripennis and $N$. giraulti (Breeuwer \& Werren, 1990).

A high number of interspecies crosses between $V$ $[V s]$ females and $G[G a]$ males yielded all male progeny even though copulations were observed. This is probably the result of insemination failure. In interspecies crosses, males have difficulty courting females of the other species (J. A. J. Breeuwer \& J. H. Werren, unpublished data). In particular, $N$. giraulti males are frequently unable to complete courtship with copulation. If copulation is terminated before sperm transfer, the female remains uninseminated and will produce all male progeny. Potentially, some of the all male progeny produced in the incompatible cross between $V[V s]$ females and $G[G s]$ males may have been the result of improper insemination. Unfortunately, transfer of sperm to the spermatheca was not assayed. Alternatively, there may be partial incompatibility between $N$. giraulti sperm and $N$. vitripennis eggs even in the absence of the cytoplasmic bacteria.

All backcrossed females with a $G$ genotype and $[V s]$ cytotype were compatible with $V[V S]$ males of similar symbiont cytotype, i.e. carried cytoplasmic bacteria of the same (vitripennis) maternal species. Conversely, these females were incompatible with $G[G s]$ males, that had similar genotypes but different symbiont cytotypes. Residual effects of introgression, e.g. genotypic incompatibility, can be ruled out in the latter, because backcrossed females were compatible with $G[G a]$ males. Moreover, even after 16 backcross generations and over a year of uncontrolled maintenance, $G 16+V$ [Vs] females remained incompatible with $G[G s]$ paternal males (Table 1). Successful introgression of the $G$ nuclear genome into a $[V S]$ cytotype is indicated, because $G 16+V[V s]$ males have the wing and anten-

Table 1 Compatibility type of females backcrossed to $N$. giraulti males, determined from crosses to the parental strains. Mean \pm s.d. is given for percentage female offspring and offspring number. Replicates are tallied by percentage female offspring. For each cross, genotype is listed first, with cytoplasmic origin between brackets. $(V=N$. vitripennis, $G=N$. giraulti, $\mathrm{s}=$ symbiont, $\mathrm{a}=$ asymbiont)

\begin{tabular}{|c|c|c|c|c|c|c|c|c|c|}
\hline \multirow[b]{3}{*}{ Cross } & \multirow[b]{3}{*}{ Female } & \multirow[b]{3}{*}{ Male } & \multicolumn{6}{|c|}{ Percentage females } & \multirow{3}{*}{$\begin{array}{l}\text { Offspring } \\
\text { number } \\
\text { Mean } \pm \text { s.d. }\end{array}$} \\
\hline & & & \multicolumn{2}{|c|}{ Incompatible } & \multicolumn{3}{|c|}{ Compatible } & \multirow[b]{2}{*}{ Mean \pm s.d. } & \\
\hline & & & 0 & $1-9$ & $10-49$ & $50-69$ & $70-100$ & & \\
\hline $\mathbf{P}$ & $V[V s]$ & $\begin{array}{l}V[V s] \\
G[G s] \\
V[V a] \\
G[G a]\end{array}$ & $\begin{array}{l}- \\
20 \\
\frac{11}{11}\end{array}$ & $\begin{array}{l}- \\
- \\
-\end{array}$ & $\begin{array}{l}- \\
- \\
1\end{array}$ & $\frac{1}{-}$ & $\begin{array}{l}28 \\
- \\
21 \\
16\end{array}$ & $\begin{array}{c}83 \pm 10 \\
0 \pm 0 \\
86 \pm 7 \\
52 \pm 43\end{array}$ & $\begin{array}{l}34.2 \pm 7.1 \\
38.3 \pm 9.5 \\
38.2 \pm 9.3 \\
34.4 \pm 7.0\end{array}$ \\
\hline B5 & $G 5 V[V s]$ & $\begin{array}{l}V[V s] \\
G[G s] \\
V[V a] \\
G[G a]\end{array}$ & $\begin{array}{l}1 \\
12 \\
- \\
-\end{array}$ & $\begin{array}{l}- \\
- \\
-\end{array}$ & $\begin{array}{l}- \\
- \\
-\end{array}$ & $\begin{array}{l}- \\
- \\
-\end{array}$ & $\begin{array}{r}10 \\
- \\
8 \\
11\end{array}$ & $\begin{array}{c}85 \pm 30 \\
0 \pm 0 \\
100 \pm 0 \\
98 \pm 4\end{array}$ & $\begin{array}{l}21.6 \pm 7.7 \\
15.8 \pm 7.7 \\
22.8 \pm 9.2 \\
35.1 \pm 9.5\end{array}$ \\
\hline B10 & $G 10 V[V s]$ & $\begin{array}{l}V[V s] \\
G[G s] \\
V[V a] \\
G[G a]\end{array}$ & $\begin{array}{l}- \\
20 \\
-\end{array}$ & $\begin{array}{l}- \\
- \\
-\end{array}$ & $\begin{array}{l}- \\
- \\
-\end{array}$ & $\begin{array}{l}- \\
- \\
-\end{array}$ & $\begin{array}{l}24 \\
\frac{1}{15} \\
17\end{array}$ & $\begin{array}{r}90 \pm 7 \\
0 \pm 0 \\
85 \pm 6 \\
87 \pm 7\end{array}$ & $\begin{array}{l}33.2 \pm 8.2 \\
37.4 \pm 9.1 \\
35.9 \pm 10.5 \\
33.8 \pm 7.4\end{array}$ \\
\hline $\mathrm{B} 16+$ & $G 16+V[V s]$ & $\begin{array}{l}V[V s] \\
G[G s]\end{array}$ & $\frac{-}{12}$ & - & 1 & $\frac{1}{-}$ & 17 & $\begin{array}{c}82 \pm 13 \\
0 \pm 0\end{array}$ & $\begin{array}{l}33.4 \pm 8.9 \\
28.3 \pm 12.2\end{array}$ \\
\hline
\end{tabular}


nal morphology of $N$. giraulti males and the marginal forewing bristles are absent in females, which is characteristic of $N$. giraulti (J. A. J. Breeuwer \& J. H. Werren, unpublished data). Compatibility type of the N. vitripennis CIM was not altered when it was associated with the $N$. giraulti genotype. In addition, the results confirm that compatibility type is a stable, cytoplasmically (maternally) inherited character.

Compatibility type of males from the same introgressed line was assessed in crosses to females of the symbiont parental strains (Table 2). The males have a $G$ genotype and $[V S]$ cytotype. Like introgressed females, they were only compatible with the parental $V$ symbiont strain and incompatible with the parental $G$ symbiont strain. These observations are consistent with the hypothesis that bidirectional cytoplasmic incompatibility is determined by differences in bacterial strains, and not due to bacterial interactions with the nuclear genome.

Despite mating observations in crosses between $G 16+V[V s]$ males and $V[V s]$ females, a high number of these crosses yielded all male progeny. This result is different from incompatibility assays of both introgressed females and males at the fifth and tenth generation of introgression. There are at least two possible explanations. First, there may be some nuclear influence over cytoplasmic incompatibility in males, that is not expressed in females from the $G 16+V[V s]$ line. However, male nuclear influence is not observed or expressed in $G 5 V[V s]$ and $G 10 V[V s]$ males. Alternatively, mating observation may not guarantee successful insemination, as suggested by the parental cross $V[V s]$ o $\times G[G a]$ o (Table 1). The latter is the most likely explanation, because $G 16+V[V s]$ males resemble $N$. giraulti males phenotypically and behaviourly. As pointed out earlier, premating discrimination between $N$. giraulti males and $N$. vitripennis females is evident.

The first backcross generations showed a reduction in offspring numbers. This probably results from hybrid breakdown when the genotypes of the two Nasonia species are combined in backcrossed individuals, and is also found in crosses using only asymbiont lines (Breeuwer, 1993). As expected, hybrid breakdown gradually disappeared by progressive introgression of $G$ into $[V s]$ cytotype and was almost absent after five backcross generations (Table 1).

\section{$\mathrm{N}$. vitripennis genotype into N. giraulti symbiont cytotype}

Introgression of $V$ genotype into $G$ cytoplasmic background was hampered by severe hybrid breakdown, which persisted over successive generations. Small offspring numbers in Table 3 are an indication of the hybrid breakdown. Moreover, after five backcross generations some males still showed $N$. giraulti wing morphology. This suggests that preferential selection for or retention of maternal $G$ genes in hybrid individuals may have occurred. Thus, substitution of $G$ with $V$ genotype in a $[G s]$ cytotype was probably lower than expected. The same phenomenon is observed when only asymbiont strains are used, indicating that the

Table 2 Compatibility type of male offspring of females backcrossed to $N$. giraulti. Mean \pm s.d. is given for percentage female offspring and offspring number. Replicates are tallied by percentage female offspring. For each cross, genotype is listed first and cytoplasmic origin is between brackets. ( $V=N$. vitripennis, $G=N$. giraulti, $\mathrm{s}=$ symbiont, a $=$ asymbiont $)$

\begin{tabular}{|c|c|c|c|c|c|c|c|c|c|}
\hline \multirow[b]{3}{*}{ Cross } & \multirow[b]{3}{*}{ Female } & \multirow[b]{3}{*}{ Male } & \multicolumn{6}{|c|}{ Percentage females } & \multirow{3}{*}{$\begin{array}{l}\text { Offspring } \\
\text { number } \\
\text { Mean } \pm \text { s.d. }\end{array}$} \\
\hline & & & \multicolumn{2}{|c|}{ Incompatible } & \multicolumn{3}{|c|}{ Compatible } & \multirow[b]{2}{*}{ Mean \pm s.d. } & \\
\hline & & & 0 & $1-9$ & $10-49$ & $50-69$ & $70-100$ & & \\
\hline $\mathrm{P}$ & $\begin{array}{l}V[V s] \\
G[G s]\end{array}$ & $V[V s]$ & $\overline{19}$ & - & - & 1 & $\begin{array}{l}28 \\
-\end{array}$ & $\begin{array}{c}83 \pm 10 \\
0 \pm 0\end{array}$ & $\begin{array}{l}34.2 \pm 7.1 \\
35.6 \pm 7.0\end{array}$ \\
\hline B5 & $\begin{array}{l}V[V s] \\
G[G s]\end{array}$ & $G 5 V[V s]$ & - & $\begin{array}{l}- \\
-\end{array}$ & $\frac{2}{-}$ & $\begin{array}{l}- \\
-\end{array}$ & $\begin{array}{c}5 \\
-\end{array}$ & $\begin{array}{c}65 \pm 31 \\
0 \pm 0\end{array}$ & $\begin{array}{l}28.6 \pm 6.7 \\
36.5 \pm 7.2\end{array}$ \\
\hline B10 & $\begin{array}{l}V[V s] \\
G[G s]\end{array}$ & $G 10 V[V s]$ & $\begin{array}{r}1 \\
22\end{array}$ & $\begin{array}{l}- \\
-\end{array}$ & $\begin{array}{l}- \\
-\end{array}$ & 1 & $\begin{array}{l}27 \\
-\end{array}$ & $\begin{array}{c}86 \pm 18 \\
0 \pm 0\end{array}$ & $\begin{array}{l}30.2 \pm 9.7 \\
35.2 \pm 9.0\end{array}$ \\
\hline B16+ & $\begin{array}{l}V[V s] \\
G[G s]\end{array}$ & $G 16+V[V s]$ & $\begin{array}{l}18 \\
26\end{array}$ & - & 1 & $\frac{1}{-}$ & $\begin{array}{l}15 \\
-\end{array}$ & $\begin{array}{c}37 \pm 41 \\
0 \pm 0\end{array}$ & $\begin{array}{l}52.4 \pm 11.7 \\
45.3 \pm 14.3\end{array}$ \\
\hline
\end{tabular}


Table 3 Compatibility type of females backcrossed to $N$. vitripennis, determined from crosses to the parental strains.

Mean \pm s.d. is given for percentage female offspring and offspring number. Replicates are tallied by percentage female offspring. For each cross, genotype is listed first and cytoplasmic origin is between brackets. $(V=N$. vitripennis, $G=N$. giraulti, $\mathrm{s}=$ symbiont, $\mathrm{a}=$ asymbiont)

\begin{tabular}{|c|c|c|c|c|c|c|c|c|c|}
\hline \multirow[b]{3}{*}{ Cross } & \multirow[b]{3}{*}{ Female } & \multirow[b]{3}{*}{ Male } & \multicolumn{6}{|c|}{ Percentage females } & \multirow{3}{*}{$\begin{array}{l}\text { Offspring } \\
\text { number } \\
\text { Mean } \pm \text { s.d. }\end{array}$} \\
\hline & & & \multicolumn{2}{|c|}{ Incompatible } & \multicolumn{3}{|c|}{ Compatible } & \multirow[b]{2}{*}{ Mean \pm s.d. } & \\
\hline & & & 0 & $1-9$ & $10-49$ & $50-69$ & $70-100$ & & \\
\hline$P$ & $G[G s]$ & $\begin{array}{l}V[V s] \\
G[G s] \\
V[V a] \\
G[G a]\end{array}$ & $\begin{array}{l}19 \\
- \\
-\end{array}$ & $\begin{array}{l}- \\
- \\
-\end{array}$ & $\begin{array}{l}- \\
- \\
-\end{array}$ & $\begin{array}{l}- \\
\frac{-}{2} \\
-\end{array}$ & $\begin{array}{l}- \\
24 \\
24 \\
22\end{array}$ & $\begin{array}{c}0 \pm 0 \\
90 \pm 6 \\
88 \pm 11 \\
80 \pm 10\end{array}$ & $\begin{array}{l}35.6 \pm 7.0 \\
38.0 \pm 8.2 \\
32.6 \pm 8.5 \\
35.9 \pm 7.1\end{array}$ \\
\hline B5 & $V 5 G[G s]$ & $\begin{array}{l}V[V s] \\
G[G s] \\
V[V a] \\
G[G a]\end{array}$ & $\begin{array}{r}9 \\
2 \\
- \\
-\end{array}$ & $\begin{array}{l}- \\
- \\
-\end{array}$ & $\begin{array}{l}- \\
- \\
-\end{array}$ & $\begin{array}{l}- \\
- \\
-\end{array}$ & $\begin{array}{r}- \\
8 \\
8 \\
11\end{array}$ & $\begin{array}{c}0 \pm 0 \\
77 \pm 41 \\
100 \pm 0 \\
98 \pm 4\end{array}$ & $\begin{array}{l}2.4 \pm 1.9 \\
7.3 \pm 4.3 \\
4.1 \pm 1.5 \\
6.7 \pm 3.1\end{array}$ \\
\hline
\end{tabular}

bacteria are not involved in retention of $G$ nuclear genes (Breeuwer, 1993).

Owing to difficulties of maintaining the stock under high levels of hybrid breakdown, introgression was stopped after five generations of backcrossing and only females could be tested. Compatibility type of $V 5 G$ $[G s]$ females is consistent with those of the reciprocal introgression; $V 5 G[G s]$ females are incompatible with $V[V s]$ males but compatible with $G[G s]$ males (Table 3 ). This suggests that incompatibility type of the $N$. giraulti cytoplasmic incompatibility micro-organism is not changed if associated with $N$. vitripennis genotype. As expected, these females were fully compatible with asymbiont males of both parental species.

\section{Discussion}

The backcross experiments demonstrate that bidirectional incompatibility between wild-type strains of $N$. vitripennis and $N$. giraulti is a cytoplasmically inherited character. The fact that compatibility types were not altered when infected cytotype of one species was associated with the genotype of the other species indicates that bidirectional incompatibility between these two Nasonia species results from differences in the symbiont bacteria of the two species, rather than interactions between the bacterial and host species genomes.

One assumption of the introgression process is that there is no preferential retention of genes of the maternal species in hybrid individuals. Violation of this assumption may affect the above interpretation that bidirectional incompatibility is caused solely by differ- ences in incompatible micro-organism strains. Hybrid breakdown could create a situation that violates this assumption. For example, certain recombinations of paternal and maternal genes in hybrids could have higher probability of surviving to adulthood than others. However, retention of specific maternal genes in itself does not necessarily affect the interpretation that compatibility type of introgressed individuals is not influenced by the host species' genotype, unless these genes play a specific role in the determination of compatibility type.

The role of bacteria in cytoplasmic incompatibility is not at issue, as bacterial curing permanently eliminates bidirectional incompatibility. What is being tested is whether differences in the bacteria are sufficient to cause bidirectional incompatibility, or whether interactions with the host genome are involved. Results indicate that the nuclear genome is not directly involved.

Both reciprocal backcrosses suffered from hybrid breakdown, i.e. a reduction in hybrid viability (Breeuwer, 1993). For the introgression of $G$ genotype into $[V s]$ cytotype, wing and antennal morphology of males and female wing bristles from the introgression line and the gradual disappearance of hybrid breakdown indicate that retention of $V$ genes did not occur. The reciprocal introgression, however, continued to suffer hybrid mortality. In addition, some male progeny of $V 5 G[G s]$ females still showed the $N$. giraulti wing morphology even though $>97$ per cent of their genotype was expected to be of $N$. vitripennis. This indicates that retention of certain $G$ genes occurred in this cross, and an influence of $G$ genotype on incompatibility 
cannot be ruled out. Nevertheless, the results are consistent with those obtained from the reciprocal introgression, that incompatibility type correlates with cytotype and is not under nuclear influence of the wasp host.

Potentially, bidirectional incompatibility could be the result of interactions between cytoplasmic incompatibility bacteria and other heritable cytoplasmic factors such as mitochondria. The introgression experiments presented here cannot rule out this possibility, because all cytoplasmic factors are transmitted together via the cytoplasm. Partial bidirectional incompatibility between two $D$. simulans strains appears to be independent of mitochondrial DNA type (Nigro, 1991). Both strains harbour cytoplasmic micro-organisms, but have different mitochondrial types. Injection of symbiont egg cytoplasm from one strain into eggs from the other symbiont strain converted compatibility type of offspring of the recipient to that of the donor, independent of whether the recipient's offspring mitochondrial type was completely replaced by the donor mitochondrial type or retained the recipient's type. It is not known to what extent mtDNA of the Nasonia species may differ.

Little is known about the actual mechanism of cytoplasmic incompatibility. Some mechanism of genomic imprinting of the paternal chromosomes by the microbes has been postulated based on two observations: maternal inheritance of the microbes and the unidirectional nature of incompatibility between asymbiont and symbiont strains (Breeuwer \& Werren, 1990; O’Neill \& Karr, 1990).

In Nasonia, cytoplasmic incompatibility results in selective elimination of the paternal chromosomes (Ryan \& Saul, 1968; Breeuwer \& Werren, 1990). Cytogenetic studies of fertilized eggs from incompatible crosses in Nasonia, revealed that the paternal chromosomes do not condense properly and fail to participate in the first mitotic division and appear to be fragmented (Ryan \& Saul, 1968; Breeuwer \& Werren, 1990). Usually the paternal chromosomes are completely lost, but occasionally small centromere-containing chromosome fragments survive and are transmitted to the next generation (Ryan et al., 1985; Beukeboom \& Werren, in press). Chromosome elimination probably also occurs in diploid incompatibility systems. Jost (1970a, b) showed that eggs are fertilized in incompatible crosses of $C$. pipiens, but developing embryos are haploid and eventually die. Abnormal mitotic divisions were observed in embryos produced in crosses between incompatible $D$. simulans strains (O'Neill \& Karr, 1990).

Many other systems are known that exhibit selective inactivation or elimination of chromosomes (see White,
1973; Sager \& Kitchin, 1975). It is postulated that in all those instances the underlying mechanisms are the same; modification and restriction of DNA $(M-R)$ by enzymes with specificity for particular recognition sites (Sager \& Kitchin, 1975). Such M-R systems are well known in bacteria and play a role in the defence against invasion of foreign DNA and exclusion of DNA of close bacterial relatives. The results of this study indicate the existence of different bacteria, and cytogenetic events that are observed in fertilized eggs of incompatible crosses may very well represent an M-R system. Obviously, further experiments are needed to elucidate the mechanism of cytoplasmic incompatibility.

Multiple incompatible crossing types, such as those observed in strains of $D$. simulans (O'Neill \& Karr, 1990; Montchamp-Moreau et al., 1991; Nigro, 1991) and C. pipiens (Laven, 1957; Subbarao et al., 1977) may also be correlated with the presence of different bacterial strains. Laven (1957, 1967), for example, already postulated the presence of several different cytoplasmically inherited factors, in the $C$. pipiens complex to explain the observed multiple crossing relationships among $C$. pipiens strains. However, multiple incompatibilities should be carefully interpreted as they do not necessarily reflect infections with different microbial strains. For example, differences in unidirectional incompatibility within $N$. vitripennis are correlated with infection levels (Breeuwer \& Werren, in press). Variation in compatibility could therefore result from variation in infection levels as well as inherent differences between bacterial strains. In diploid species, hybrid breakdown among both sexes as a result of nuclear-nuclear or nuclear-cytoplasmic interactions could potentially generate incompatibility relationships similar to micro-organism-induced incompatibility. In both cases the number of offspring will be reduced and are, without further experiments, indistinguishable from micro-organism-induced cytoplasmic incompatibility. For example, in $D$. simulans, crosses which involved transformed male individuals that had both mitochondrial types present, produced significantly fewer offspring compared with crosses with transformed individuals that were fixed for either recipient or donor mitochondrial type (Nigro, 1991).

Other mechanisms, such as nuclear effects with parental expression (Rousset et al., 1991) or cytoplasmic conditioning alleles and preferential segregation (see McClelland, 1967) have been postulated to account for the phenomenon of bidirectional incompatibility. Introgression studies in conjunction with antibiotic treatment are one way to determine the independence between cytoplasmic incompatibility microbes and their host genome in bidirectional incompatible crosses. Injection of microbes from one 
host species into another host strain may provide an alternative technique that separates microbes from nuclear and other cytoplasmic factors (Nigro, 1991).

In conclusion, results from the backcrossing experiments show that bidirectional cytoplasmic incompatibility between $N$. vitripennis and $N$. giraulti is based on the presence of different CIM in each of the Nasonia species. There does not appear to be a direct nuclear involvement. These incompatibility systems provide opportunities to study mechanisms of DNA modification or genomic imprinting because they are easy to manipulate and are caused by discrete elements: heritable micro-organisms. They also provide excellent systems to study evolution between hosts and their parasites.

\section{Acknowledgements}

We thank Kent Reed for reviewing earlier drafts and Ed Quallen, Madeline Bryant, Misty Ritchie and Julie Chen for help with courtship observations and counting. This research was supported by NSF grant BSR8906231.

\section{References}

BEUKEBOOM, L. W. AND WERREN, J. H. Deletion analysis of a parasitic B chromosome-paternal sex ratio (PSR). Genetics, in press.

BINNINGTON, K. C. AND HOFFMANN, A. A. 1989. Wolbachia-like organisms and cytoplasmic incompatibility in Drosophila simulans. J. Invert. Pathol., 54, 344-352.

BREEUER, J. A. AND WERREN, J. H. Cytoplasmic incompatibility and bacterial density in Nasonia vitripennis. Genetics, in press.

BREEUWER, J. A. J., STOUTHAMER, R., BARNS, S. M., PELLETIER, D. A., WEISBURG, W. G. AND WERREN, J. H. 1992. Phylogeny of cytoplasmic incompatibility microorganisms in the parasitoid wasp genus Nasonia (Hymenoptera, Pteromalidae) based on $16 \mathrm{~S}$ ribosomal DNA sequences. Insect Mol. Biol., 1,25-36.

BREEUWER, J. A. J. AND WERREN, J. H. 1990. Microorganisms associated with chromosome destruction and reproductive isolation between two insect species. Nature, 346, 558-560.

BREEUER, J. A. 1993. The role of cytoplasmic microorganisms and other heritable cytoplasmic factors. Ph.D. Thesis. University of Rochester, Rochester, NY.

DARLing, D. C. AND WERREN, J. H. 1989. Biosystematics of Nasonia (Hymenoptera, Pteromalidae), two new species reared from birds' nests in North America. Ann. Ent. Soc. Am., 83, 352-369.

GRUN, P. 1976. Cytoplasmic Genetics and Evolution, Columbia University Press, New York.

HOFFMANN, A. A. 1988. Partial cytoplasmic incompatibility between two Australian populations of Drosophila melanogaster. Entomol. Exp. Appl., 48, 61-67.
HOFFMANN, A. A. AND TURELLI, M. 1988. Unidirectional incompatibility in Drosophila simulans. Inheritance, geographic variation and fitness effect. Genetics, 119, 435-444.

HOFFMANN, A. A., TURELl, M. AND SIMMONS, G. M. 1986. Unidirectional incompatibility between populations of Drosophila simulans. Evolution, 40,692-701.

HSIAO, C. AND HSIAO, T. H. 1985a. Rickettsia as the cause of cytoplasmic incompatibility in the alfalfa weevil, Hypera postica. J. Invert. Pathol., 45, 244-246.

HSIAO, T. H. AND HSIAO, C. 1985b. Hybridization and cytoplasmic incompatibility among alfalfa weevil strains. Entomol. Exp. Appl., 37, 155-159.

JOST, E. 1970a. Untersuchungen zur Kreuzungs Sterilität im Culex pipiens Komplex. Wilhelm Roux Arch. Entwick. Org., 166, 173-188.

JOST, E. 1970 b. Genetische Untersuchungen zur Inkompatibilität im Culex-pipiens-Komplex. Theor. Appl. Genet., 40, 251-256.

KELLEN, W. R., HOFFMANN, D. F. AND KWOCK, R. A. 1981. Wolbachia sp. (Rickettsiales, Rickettsiaceae) a symbiont of the almond moth, Ephestia cautella, ultrastructure and influence on host fertility. J. Invert. Pathol., 37, 273-283.

LAVEN, H. 1957. Verebung durch Kerngene und das Problem der ausserkaryotischen Vererbung bei Culex pipiens. II Ausserkaryotische Vererbung. Z. Indukt. Abstamm. Vererbungsl., 88, 478-516.

LAVEN, H. 1967. Speciation and evolution in Culex pipiens. In: J. W. Wright and R. Pal (eds) Genetics of Insect Vectors of Diseases, Elsevier Publications, Amsterdam, pp. 251-275.

MCClelland, G. A. H. 1967. Speciation and evolution in Aedes. In: J. W. Wright and R. Pal (eds) Genetics of Insect Vectors of Diseases, Elsevier Publications, Amsterdam, pp. 277-311.

MONTCHAMP-MOREAU, C., FERVEUR, J. AND JACQUES, M. 1991. Geographic distribution and inheritance of three cytoplasmic incompatibility types in Drosophila simulans. Genetics, 129, 399-407.

NIGRO, L. 1991. The effect of heteroplasmy on cytoplasmic incompatibility in transplasmic lines of Drosophila simulans showing a complete replacement of the mitochondrial DNA. Heredity, 66, 41-45.

O'NEILL, s. L. 1989. Cytoplasmic symbionts in Tribolium confusum. J. Invert. Pathol., 53, 123-124.

O'NEILL, S. L., GIORDANO, R., COLBERT, A. M. E., KARR, T. L. AND ROBERTSON, H. M. 1992. 16S rRNA phylogenetic analysis of the bacterial endosymbionts associated with cytoplasmic incompatibility in insects. Proc. Natl. Acad. Sci., U.S.A., 89, 2649-2702.

O'NEILL, S. L. AND KARR, T. L. 1990. Bidirectional incompatibility between conspecific populations of Drosophila simulans. Nature, 348, 178-180.

RICHARDSON, P. M., HOLMES, W. P. AND SAUL II, G. B. 1987. The effect of tetracycline on nonreciprocal cross incompatibility in Mormoniella [ = Nasonia $]$ vitripennis. J. Invert. Pathol., 50, 176-183.

ROUSSET, F., RAYMOND, M. AND KJELLBERG, F. 1991. Cytoplasmic incompatibilities in the mosquito Culex pipiens: How to explain a cytotype polymorphism? J. Evol. Biol., 4, 69-81. 
ROUSSET, F., VAUGHIN, D. M. AND SOLIGNAC, M. 1992. Molecular identification of Wolbachia, the agent of cytoplasmic incompatibility in Drosophila simulans, and variability in relation to host mitochondrial types. Proc. R. Soc. Lond. $B, \mathbf{2 4 7}, 163-168$.

RYAN, S. L. AND SAUL II, G. B. 1968. Post-fertilization effect of incompatibility factors in Mormoniella. Molec. Gen. Genet., 103, 29-36.

RYAN, S. L., SAUl II, G. B. AND CONNER, G. W. 1985. Aberrant segregation of R-locus genes in male progeny from incompatible crosses in Mormoniella. J. Hered., 76, 21-26.

SAGER, R. AND KITCHIN, R. 1975. Selective silencing of eukaryotic DNA. Science, 189, 426-433.

SAUL, G. B. 1961. An analysis of non-reciprocal cross incompatibility in Mormoniella vitripennis (Walker). Z. Vererbungslehre, 92, 28-33.

SUBBARAO, S. K., KRISHNAMURTHY, B. S., CURTIS, C. F., ADAK, T. AND CHANDRAHAS, R. K. 1977. Segregation of cytoplasmic incompatibility properties in Culex pipiens fatigans. Genetics, 87, 381-390.
TRPIS, M., PERRONE, J. B., REISSIG, M. AND PARKER, K. L. 1981. Control of cytoplasmic incompatibility in the Aedes scutellaris complex. J. Hered., 72, 313-317.

WADE, M. J. AND STEVENS, L. 1985. Microorganism mediated reproductive isolation in flour beetles (Genus Tribolium). Science, 278, 527-528.

white, M. J. D. 1973. Animal Cytology and Evolution. Cambridge Univesity Press, Cambridge.

Whiting, A. R. 1967. The biology of the parasitic wasp Mormoniella vitripennis. $Q$. Rev. Biol., 42, 333-406.

WRIGHT, J. D. AND BARR, R. A. 1980. The ultrastructure and symbiotic relationships of Wolbachia of mosquitoes of the Aedes scutellaris group. J. Ultrastruct. Res., 72, 52-64.

YEN, J. H. AND BARR, A. R. 1971. New hypothesis of the cause for cytoplasmic incompatibility in Culex pipiens. J. Invert. Pathol., 22, 242-250.

YEN, J. H. AND BARR, A. R. 1973. The etiological agent of cytoplasmic incompatibility in Culex pipiens. J. Invert. Pathol., 22, 242-250. 